\title{
Assessment of physical activity, capacity and nutritional status in elderly peritoneal dialysis patients
}

\author{
Adamasco Cupisti ${ }^{1 *}$, Claudia D'Alessandro ${ }^{1}$, Viviana Finato ${ }^{2}$, Claudia Del Corso ${ }^{3}$, Battista Catania ${ }^{4}$, \\ Gian Marco Caselli ${ }^{5}$ and Maria Francesca Egidi ${ }^{1}$
}

\begin{abstract}
Background: This study aimed to evaluate the prevalence of sedentarism, and to assess physical capacity and nutritional status in a cohort of older patients on peritoneal dialysis (PD), with respect to age-matched non-dialysis CKD population, using highly accessible, simple methods, namely the Rapid Assessment of Physical activity (RAPA) test and the 30" Sit-to-stand (STS) test.

Methods: This cross-sectional multicenter study included 151 renal patients older than 60 years; 71 pts. (44 m, age $72 \pm 7$ yrs) were on PD and 80 pts. (63 m, age $74 \pm 7$ yrs) were affected by 3-4 stage CKD.

Results: The prevalence of sedentary/underactive patients was double of that of the active patients as assessed by RAPA test, both in the PD (65.3\%) and in the CKD (67.5\%) cohort.

The 30"STS test showed a reduced physical performance in both groups: $84.5 \%$ of PD patients and $87.5 \%$ of CKD patients did not reach the expected number of stands by age and gender. A malnutrition-inflammation score (MIS) $\geq 6$ occurred in $37 \%$ of PD patients and in $2.5 \%$ of CKD patients. In PD patients, an independent significant association was observed between 30"STS test and MIS (beta $-0.510, p=0.013$ ), as well as between RAPA and MIS (beta $-0.544, p=003$ ) and phase angle (beta $-0.506, p=0.028$ ).

Conclusions: A high prevalence of low- performance capacity and sedentarism has been detected among elderly patients on PD or with CKD stage 3-4. Apart from age, a condition of malnutrition-inflammation was the major determinant of poor physical activity and capacity in PD patients. Better body composition seems to be positively associated with physical activity in PD and with physical capacity in CKD patients. Routine clinical management should include a close evaluation of nutritional status and evaluation of physical activity and capacity which can be easily assessed by RAPA and 30"STS tests.
\end{abstract}

Keywords: Physical activity, Nutritional status, Peritoneal dialysis, Esrd, MIS, Rapa, CKD, Performance

\section{Background}

The treatment of chronic kidney disease (CKD) aims to reduce progression of renal and cardiovascular damage, so as to prevent uremic complications and to improve survival. However, new challenges must be addressed to ameliorate the health status and to prevent disability. A proper nutritional approach and regular physical activity are important to improve the quality of life and to

\footnotetext{
* Correspondence: adamasco.cupisti@med.unipi.it

${ }^{1}$ Department of Clinical and Experimental Medicine, University of Pisa, Via

Roma 67, 56126 Pisa, Italy

Full list of author information is available at the end of the article
}

maintain physical performance and ability in renal patients [1].

Physical inactivity is a long-standing clinical problem among pre-dialysis CKD patients [2] and end-stage renal disease (ESRD) patients on dialysis treatment [3]. It contributes to disability and to poor nutritional status that is associated with increased morbidity and mortality risk.

Evidence exists of an association between sedentary behavior and mortality in ESRD patients $[4,5]$. In survival analysis, sedentary behavior was associated with an increased risk for death at 1-year follow-up after adjusting for all the variables linked to the mortality risk [6]. 
Advancing age is another major determinant of physical functioning and a sedentary lifestyle is largely prevalent in elderly people, including renal patients. Protein energy wasting (PEW) is another condition that is associated with disability, frailty and low physical activity and capacity [7]. PEW is quite prevalent in CKD and ESRD patients, including PD patients [8]. Since the PD is a suitable method for the increased amount of elderly patients with ESRD [9], nutritional and physical functioning evaluation is an outstanding aspect of the clinical management.

The aim of the study was to evaluate the prevalence of low physical activity, and to assess physical capacity and nutritional status in a cohort of PD older patients with respect to age-matched non-dialysis CKD population, using highly accessible, simple methods. The determinants of hypo-activity were also investigated.

\section{Methods}

This is a cross-sectional case-control multicenter study that included 151 prevalent renal patients aged older than 60 years; 71 pts. $(44 \mathrm{~m}, 27 \mathrm{f}$, age $72 \pm 7$ yrs) were on PD by $33 \pm 20$ months, and 80 pts. $(63 \mathrm{~m}, 17 \mathrm{f}$, age $74 \pm 7$ yrs) affected by CKD stages $3-4$ were on tertiary care management. Five peritoneal dialysis units sited in Tuscany (Pisa, Pontedera, S. Miniato, Pistoia and Florence) participated in the study.

Patients with physical or neurological disability, muscular diseases or lower-limb amputation were excluded as well as those with acute illness or infections, severe heart or respiratory insufficiency, peritonitis or patients on CKD stage 5-ND.

All the patients underwent an evaluation of their physical function and nutritional status in an out-patients clinic setting, during the period from 1st January to 31st December 2015.

Spontaneous physical activity and physical performance were detected using the rapid assessment of physical activity (RAPA) and the 30" Sit-to-Stand (30" STS) chair test, respectively.

The RAPA is a validated test able to assess habitual physical activity in adults older than 50 years [10]. The RAPA was administered to the patients before the visit to the renal out-patient clinic. RAPA test score $\leq 3$ corresponded to a sedentary lifestyle or a very light activity level; values $\geq 4$ indicated a moderate to vigorous active lifestyle [10].

The 30" STS chair test is a validated test able to assess lower extremity strength in adults older than 60 years [11]. In the 30" STS chair test the participant is seated in the chair with his/her arms crossed and held against the shoulders. The score correspond to the number of stands a person can complete in 30 " without the help of arms. Data were compared also with standard values for age and gender $[11,12]$.

Anthropometry was performed at the out-patient clinic, with empty abdomen in PD patients. It included measurements of body weight, height, triceps skinfold thickness and body circumferences such as middle arm, hip and waist [13]. Body mass index, and middle arm muscle circumference were calculated. As body composition analysis parameters, we reported phase angle and Body mass cell index [14] detected by Bio-Impedance Analysis (BIA). Phase angle $<5.0^{\circ}$ in men and $<4.9^{\circ}$ in women have been assumed as cut-off values for risk of under-nutrition [15].

Biochemical evaluation was performed after an overnight fasting and included: urea, creatinine, electrolytes, bicarbonate, albumin, 25(OH)VitD serum levels and hemoglobin. Renal function in CKD patients was reported as estimated GFR (eGFR), using CKD-EPI creatinine formula.

Demographic and clinical data, and comorbidities were extracted by patient's medical chart. Charlson comorbidity index (CCI) was calculated accordingly.

Malnutrition Inflammation Score [16, 17], was calculated as follows: scores $6-10$ were indicative of mild malnutrition and score $\geq 11$ were indicative of severe malnutrition. An appetite questionnaire, namely the council of nutrition appetite questionnaire (CNAQ), was self-administered [18]. The Geriatric Nutritional Risk Index (GNRI) is a very simple and objective method to assess nutritional status in a number of pathological conditions, including dialysis patients [19-21]. It is based on body weight, height and serum albumin levels. The GNRI was calculated by modifying the Nutritional risk index for elderly patients [22] as follows: GNRI $=[14.89 *$ albumin $(\mathrm{g} / \mathrm{dl})]+[41.7 *$ (body weight $/$ ideal body weight)]. As body weight we considered the value in the morning, at empty abdomen: it was also the value used for body mass index (BMI) calculation (expressed as $\mathrm{kg} / \mathrm{m}^{2}$ ); body weight/ideal body weight was set to 1 when the patient's body weight exceeded the ideal body weight [5]. The ideal body weight in the present study was assumed as the value calculated from the height to obtain a BMI of $22.5 \mathrm{~kg} / \mathrm{m}^{2}$, which is the reference for the Italian population.

Patients gave their informed consent to participate in the study which was in accordance with the Helsinki declaration. The study protocol was approved by the Local Ethics Committee of Pisa University Hospital.

\section{Statistical analysis}

Data are expressed as mean \pm standard deviation (SD) or median and inter-quartile range (IQR) when appropriate. Comparisons between groups were assessed by Mann-Whitney $U$ test for independent 
samples. Chi-square test was used for analysis of frequencies. Spearman linear correlation analysis was used to determine associations between various selected parameters.

Multivariate statistical analysis was conducted for examining the effect of multiple independent variables, namely age, gender, Charlson Comorbidity Index, Appetite Score. Malnutrition Inflammation Score, phase angle and BCMI on physical capacity assessed by the 30" STS chair test or on physical activity assessed by RAPA test.

Statistical evaluation was performed using IBM SPSS statistics version 19 (SPSS Inc., Illinois, USA) for Windows.

Differences were considered as statistical significant when $p<0.05$.

\section{Results}

Clinical features of PD and CKD patients are reported in Table 1.

Thirty-six PD patients were on continuous ambulatory peritoneal dialysis (CAPD) (50.7\%) and 35 (49.3\%) were on automated peritoneal dialysis (APD). Weekly $\mathrm{Kt} / \mathrm{V}$ in the PD group resulted $2.0 \pm 0.5$. In the CKD group, eGFR was $32 \pm 12 \mathrm{ml} / \mathrm{min}^{*} 1.73 \mathrm{~m}^{2}$, range $16-59 \mathrm{ml} / \mathrm{min}^{*} 1.73 \mathrm{~m}^{2}$.

Table 1 Clinical features of peritoneal dialysis (PD) and chronic renal disease (CKD) patients. Data are reported as Median (IQR)

\begin{tabular}{|c|c|c|}
\hline & PD & CKD \\
\hline & $n=71$ & $n=80$ \\
\hline Age, years & $73.0(68.0-76.0)$ & $75.0(69.0-80.8)$ \\
\hline Body weight, Kg & $72.5(62.5-87.0)^{*}$ & $78.0(71.6-87.3)$ \\
\hline $\mathrm{BMI}, \mathrm{Kg} / \mathrm{m}^{2}$ & $26.0(22.4-29.4)^{*}$ & $27.6(25.3-30.9)$ \\
\hline Charlson Index & $7.0(5.0-8.0)$ & $7.0(6.0-8.0)$ \\
\hline MIS & $5.0(3.0-6.0)^{* * *}$ & $0(0-2.0)$ \\
\hline Appetite (CNAQ) & $29.0(25.0-32.0)^{* *}$ & $31.0(29.0-32.0)$ \\
\hline GNRI & $95.7(90.8-100)^{* * *}$ & $103(98.5-107)$ \\
\hline RAPA & $3.0(2.0-4.0)^{*}$ & $2.0(0-5.0)$ \\
\hline 30" STS, n.stands & $10.5(8.8-13.0)$ & $10.0(8.0-12.0)$ \\
\hline sUrea, mg/dl & $124(105-150)^{* * *}$ & $81.1(61.0-97.0)$ \\
\hline sCreatinine, mg/dl & $7.8(5.8-9.2)^{* * *}$ & $2.0(1.5-2.8)$ \\
\hline sAlbumin, g/dl & $3.6(3.3-3.8)^{* * *}$ & $4.2(3.9-4.4)$ \\
\hline Haemoglobin, g/dl & $11.5(10.8-12.2)^{* * *}$ & $13.0(11.8-14.7)$ \\
\hline sPhosphate, mg/dl & $4.7(3.9-5.3)^{* * *}$ & $3.3(2.9-3.7)$ \\
\hline sCalcium, mg/dl & $9.2(8.7-9.4)^{*}$ & $9.3(9.1-9.6)$ \\
\hline sSodium, mEq/l & $140(137-142)^{* *}$ & $141(139-142)$ \\
\hline sPotassium, mEq/l & $4.2(3.8-4.9)^{* * *}$ & $4.6(4.4-5.1)$ \\
\hline sBicarbonate, mM & $25.2(23.1-28.0)^{*}$ & $24.4(22.0-26.7)$ \\
\hline $250 H$ Vit D, ng/ml & $13.4(8.6-23.2)$ & $21.9(15.4-28.1)$ \\
\hline
\end{tabular}

GNRI geriatric nutrition risk index, MIS malnutrition inflammation score, CNAQ council of nutrition appetite questionnaire, $B M I$ body mass index, GNRI geriatric nutrition risk index; 30 "STS: 30 "Sit-to-Stand

${ }^{*} p<0.05$, ${ }^{* *} P<0.01,{ }^{* * *} P<0.001$ vs CKD
As expected, PD patients had more pronounced metabolic abnormalities and serum albumin markedly lower than CKD patients. Hemoglobin level was lower in PD patients but it was well in accordance with the current recommendations. A good control of serum potassium and of metabolic acidosis was detected in PD group, while a vitamin D deficiency was quite prevalent in both groups [Table 1].

The CCI indicated a very similar level of comorbidity. Instead, MIS was markedly higher in PD than in CKD patients (Table 1). A MIS score suggestive of malnutrition $(\geq 6)$ occurred in $37 \%$ of PD patients and $2.5 \%$ of CKD patients (Fig. 1). A GNRI score $<92$, as suggestive of a poor outcome, was found in $31 \%$ of PD patients and $3.8 \%$ of CKD patients $(p<0.001)$. In Table 2 some nutritional aspects of PD and CKD patients are reported, by gender.

The reported level of RAPA score was similar in PD e CKD patients (Tables 1-2).

The prevalence of sedentary/underactive patients was roughly double than that of active patients as assessed by RAPA. Namely, $65.3 \%$ of PD patients and $67.5 \%$ of CKD patients resulted sedentary/underactive by the RAPA test; no difference was detected between PD and CKD groups (Fig. 2).

When compared to PD patients who reported moderate to vigorous physical activity, sedentary/underactive PD patients were older and had a higher MIS score, lower appetite score, lower GNRI, worse performance at the STS test, and a reduced middle arm muscle circumference (Table 3). Phase angle values $<5.0^{\circ}$ in men or $<4.9^{\circ}$ in women were detected in $50 \%$ of patients of the under-active group and in $18 \%$ of the active group.

The results of the 30"STS tests were not different between CKD and PD patients (Tables 1-2). As a whole, the age-related average number of repetitions to the 30 " STS test resulted lower than expected both in males and females, but similar between PD and CKD patients (Fig. 3). $84.5 \%$ of PD patients and $87.5 \%$ of CKD patients did not reach the expected number of stands by age and gender to maintain physical activity.

No difference was detected between patients on CAPD and APD as far as nutritional status, RAPA or 30"STS test were concerned.

In PD patients linear correlation analysis showed that the STS performance negatively correlated to age $(r=-0.295, p<0.05)$ and MIS $(r=-0.424, p<0.01)$ and positively to appetite score $(r=0.255, p<0.05)$. The same significant correlations were observed for the RAPA score (age: $r=-0.413, p<0.01$; MIS: $r=-0.595$, $p<0.01$; appetite score: $r=0.395, p<0.01$ ).

In CKD patients STS performance was negatively associated with MIS $(r=-0.255, p<0.05)$.

Multivariate statistical analysis was performed to analyze the effect of multiple independent variables, namely age, 


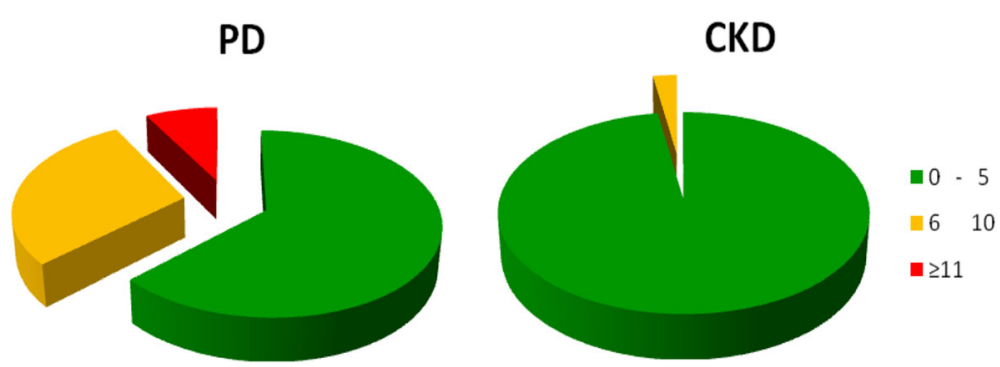

Fig. 1 Malnutrition Inflammation Score in the Peritoneal Dialysis (PD) and in the chronic kidney disease (CKD) patients cohorts. A score $0-5$ is indicative of normal nutrition (green); 6-10 score is indicative of mild malnutrition (orange), while score $\geq 11$ is suggestive of moderate to severe malnutrition (red)

gender, Charlson Comorbidity Index, Appetite Score, MIS, phase angle and BCMI, on physical performance assessed by the 30" STS chair test.

In PD patients, an independent significant association was observed between 30"STS test and MIS (beta -0.510 , $p=0.013$ ), as well as between RAPA and MIS (beta -0.544 , $p=0.003$ ) and phase angle (beta $-0.506, p=0.028$ ).

In CKD patients the multivariate analysis showed an independent significant association between 30"STS test and gender (beta $-0.276, p=0.020$ ) and BCMI (beta $-0.328, p=0.009$ ).

\section{Discussion}

The results of our study indicate that PD patients are largely inactive as detected by RAPA test and have a low-level of physical performance as detected by the 30 "STS test. This occurred when data were compared to regular standards. However, when performance level of
PD patients were compared with the cohort of nondialysis CKD patients no difference emerged.

It suggests that peritoneal dialysis per se' is not a major cause of worsening of physical activity and performance. Instead, malnutrition-inflammation was the major determinant of physical impairment in our PD cohort, where higher physical activity was associated with better body composition.

A number of studies addressed physical functioning in ESRD patients but few papers have been focused on physical activity and performance in PD patients, especially in the elderly cohort.

Our data are well in keeping with those of Cobo et al., who reported a high prevalence of sedentary lifestyle (63\%) in a cohort of 64 PD patients as assessed by pedometers [23]. They found that better physical activity was associated with better nutritional status and lower comorbidity [23]. It is noteworthy that those patients were approximately 10 years younger than our cohort.

Table 2 RAPA and 30"STS test, and parameters of nutritional status in peritoneal dialysis (PD) and chronic kidney disease (CKD) patients by gender. Data are reported as Median (IQR)

\begin{tabular}{|c|c|c|c|c|}
\hline & \multicolumn{2}{|l|}{ Males } & \multicolumn{2}{|l|}{ Females } \\
\hline & $\begin{array}{l}P D \\
n=44\end{array}$ & $\begin{array}{l}C K D \\
n=63\end{array}$ & $\begin{array}{l}\mathrm{PD} \\
n=27\end{array}$ & $\begin{array}{l}\text { CKD } \\
n=17\end{array}$ \\
\hline Age, years & $73.0(66.3-76.0)$ & $75.0(69.0-81.0)$ & $70.0(64.0-76.0)$ & $75.0(66.0-78.5)$ \\
\hline Body weight, $\mathrm{Kg}$ & $78.6(71.6-90.4)$ & $78.6(72.7-88.8)$ & $61.3(55.7-72.0) *$ & $70.0(64.3-83.3)$ \\
\hline $\mathrm{BMI}, \mathrm{Kg} / \mathrm{m}^{2}$ & $26.7(22.7-29.9)$ & $27.5(25.5-30.7)$ & $24.0(22.0-28.2)$ & $28.2(24.8-33.7)$ \\
\hline RAPA Test 1 & $3.0(2.0-4.8)$ & $2.0(0-5.0)$ & $2.0(1.0-4.0)$ & $2.0(0.5-2.0)$ \\
\hline Sit-to-stand (30 "), n. stands & $10.0(9.0-12.0)$ & $11.0(8.0-13.0)$ & $11.0(8.0-13.0)$ & $8.0(7.0-10.0)$ \\
\hline Waist Circumference, cm & $105(98.0-119)$ & $103(96.5-109)$ & $96.0(85.0-102)$ & $97.0(88.0-107)$ \\
\hline Hip Circumference, $\mathrm{cm}$ & $107(100-115)$ & $104(99.0-109)$ & $98.0(94.0-106) *$ & $109(102-114)$ \\
\hline TST, cm & $1.0(0.6-2.1)$ & $1.0(0.7-1.3)$ & $0.7(0.4-1.0) *$ & $1.8(1.1-2.3)$ \\
\hline $\mathrm{MAC}, \mathrm{cm}$ & $29.0(27.0-31.0)$ & $29.0(27.0-32.0)$ & $27.0(25.2-31.0)$ & $29.7(26.1-34.0)$ \\
\hline MAMC, cm & $26.3(22.4-28.0)$ & $25.8(24.3-27.9)$ & $25.6(22.2-29.5)$ & $25.0(21.2-28.6)$ \\
\hline Phase angle, ${ }^{\circ}$ & $5.5(4.3-6.2)$ & $4.9(4.3-5.5)$ & $5.0(4.2-5.4)$ & $4.3(4.1-4.9)$ \\
\hline $\mathrm{BCMl}, \mathrm{Kg} / \mathrm{m}^{2}$ & $8.5(7.6-10.3)$ & $9.2(8.1-10.5)$ & $7.3(6.1-8.4)$ & $7.7(7.0-8.2)$ \\
\hline
\end{tabular}

TST triceps skinfold thickness, MAC middle arm circumference, MAMC middle arm muscle circumference, $B M I$ body mass index, RAPA rapid assessment of physical activity, TST triceps skinfold thickness, $B C M I$ body cell mass index ${ }^{*} p<0.05$ vs CKD 


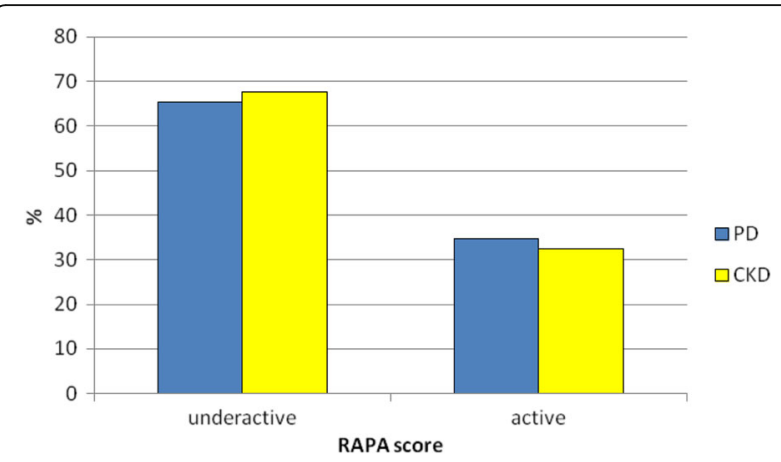

Fig. 2 Prevalence of sedentary/underactive or moderate to vigorous active patients as assessed by RAPA test (score $\leq 3$ or $\geq 4$, respectively) in the PD and CKD studied cohorts

Pedometers and other wearable devices such as the sense-wear arm-band [24, 25] are useful and reliable tools to assess physical activity level in the daily life. However, limited resources or poor patient's compliance may prevent a widespread applications of these devices in the clinical management of CKD and ESRD populations. RAPA and 30"STS have the advantages to be simple, less time consuming, inexpensive and feasible in all clinical settings.

The RAPA test has been validated as a tool for the assessment of physical activity in adults older than 50 years [10]. It is very simple test, self-administered,

Table 3 Differences between PD patients assessed as sedentary/underactive or moderately to vigorously physically active by RAPA test scoring. Data are reported as Median (IQR)

\begin{tabular}{|c|c|c|c|}
\hline & Underactive & Active & $p$ \\
\hline Age, years & $75.0(69.8-79.0)$ & $68.0(63.0-73.0)$ & $<0.001$ \\
\hline $\mathrm{BMl}, \mathrm{Kg} / \mathrm{m}^{2}$ & $25.8(22.0-29.0)$ & $26.0(22.9-30.5)$ & n.s. \\
\hline MIS & $6.0(4.0-7.5)$ & $3.0(2.0-4.0)$ & $<0.001$ \\
\hline GNRI & $95.3(90.5-98.1)$ & 98.7(95.3-102) & $<0.05$ \\
\hline Appetite, CNQA & $28.0(23.8-31.0)$ & $30.0(28.5-32.0)$ & $<0.01$ \\
\hline sUrea, mg/dl & $120(109-144)$ & $136(98.7-159)$ & n.s. \\
\hline sCreatinine, mg/dl & $7.7(5.8-9.2)$ & $8.0(5.9-9.7)$ & n.s. \\
\hline sAlbumin, g/dl & $3.6(3.3-3.7)$ & $3.7(3.3-3.9)$ & n.s. \\
\hline Haemoglobin, g/dl & $11.5(10.8-12.1)$ & $12.0(10.0-14.0)$ & n.s. \\
\hline 30"STS, n. stands & $10.0(6.5-12.0)$ & $12.0(10.0-14.0)$ & $<0.01$ \\
\hline Waist circumference, $\mathrm{cm}$ & $101(92.5-111)$ & $100(87.0-115)$ & n.s. \\
\hline $\mathrm{MAC}, \mathrm{cm}$ & $28.5(25.9-31.0)$ & $30.0(26.5-33.5)$ & n.s. \\
\hline MAMC, cm & $24.0(22.0-27.6)$ & $27.5(25.6-29.0)$ & $<0.05$ \\
\hline Phase angle, ${ }^{\circ}$ & $4.9(3.7-5.9)$ & $5.4(5.0-6.2)$ & n.s. \\
\hline $\mathrm{BCMI}, \mathrm{Kg} / \mathrm{m}^{2}$ & $7.9(6.7-9.5)$ & $8.2(7.3-10.5)$ & n.s \\
\hline
\end{tabular}

PA physical activity, BMI body mass index, MAC middle arm circumference, MAMC middle arm muscular circumference, GNRI geriatric nutrition risk index, MIS malnutrition inflammation score, CNAQ council of nutrition appetite questionnaire, $B C M I$ body cell mass index and not time-consuming. It has all the limits of the self-reporting test, but it may be very useful for an extensive routine implementation in the daily life clinical practice. It has been favorably tested also as a telephone-based questionnaire [26].

Similarly, 30" Sit-to-Stand test [11] is a validated test able to assess functional lower extremity strength in adults older than 60 years. It is easy to perform everywhere and takes very little time. The scoring is predictive of functional capacity and is related to nutritional status and prognosis in several chronic diseases [12].

Malnutrition-inflammation seems to be one of the major determinant of physical impairment in our PD cohort. Moreover, this condition may be favored by the high protein loss, and by the abdominal discomfort and glucose load that may induce loss of appetite, that is quite prevalent in PD patients.

The negative relationship between STS test and MIS and between RAPA test score and MIS observed in our PD patients is of interest and it is in accordance with other reports. MIS was found to be a reliable prognostic predictor [16], which was associated to the level of physical performance and functional capacity of PD patients [27].

It has been reported that dialysis patients with laboratory-based evidence of malnutrition and/or inflammation were likely to report lower levels of physical activity $[28,29]$. It is noteworthy that exercise could evoke anti inflammatory effects in predialysis CKD patients [30].

In the PD patients, physical activity was associated with better body composition. Similarly, in the CKD group, physical performance was positively related to higher body cell mass index. Although these results may be quite expected and do not demonstrate causality, they confirm that body composition and functional aspects are closely related and inter-dependent in renal patients.

Moreover, favorable effects of physical activity implementation have been described [3] including psychological and health perception effects [31]. This may be a further reason to stimulate physical exercise programs in the ESRD population [32].

The relationship between nutritional status and physical activity is of special value in PD patients who are, on one side, at high risk of protein depletion, and on the other side at risk of obesity $[8,33]$. In this clinical setting, implementation of a regular physical activity could contribute to maintain muscle mass and to increase energy expenditure.

Unfortunately, many barriers prevent a regular assessment of physical activity and implementation of exercise programs in ESRD patients [34, 35]. 

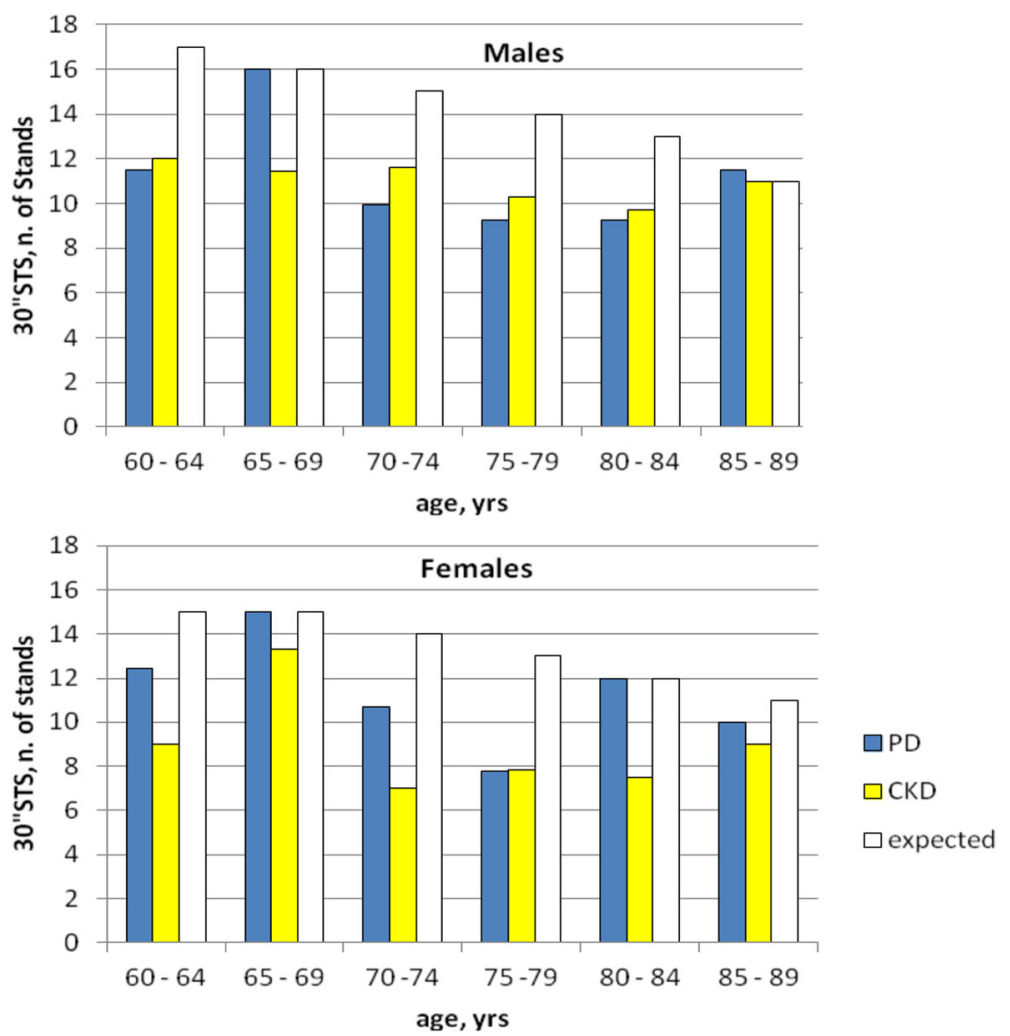

Fig. 3 Average number of stands to the 30" sit-to-stand (30"STS) test in males and females. The empty column represents the number of stands (by sex and age) predictive of physical activity maintenance

Studies have shown a progressive decline of physical function with declining GFR, and cross-sectional and observational studies have shown relationships between declining GFR and physical function, muscle mass and performance [36-38]. In the present study, we failed to find a relationship between eGFR and physical activity level, and no major differences in physical activity and capacity were detected between CKD and PD patients. This discrepancy may be justified, in part at least, by the fact that our patients were already on tertiary care and received standard nutritional and pharmacological therapies, consequently most patients were on a quite good metabolic control. In addition, we used RAPA and 30 "STS tests because they are easy to be applied in the real-life setting. However, we appreciate that they have less sensibility and specificity than other methods exploring physical activity and capacity, and this may limit also the sensitivity of statistical analysis in a quite small group of patients.

Finally, we confirm that vitamin D deficiency is quite prevalent in PD patients. Treatment with Vitamin D may be useful in PD patients, where an increase of the functional capacity has been also reported [39].

\section{Conclusions}

A high prevalence of low- performance capacity and sedentarism has been detected among elderly patients on PD or with CKD stage 3-4. Apart from age, a condition of malnutrition-inflammation was the major determinant of poor physical activity and capacity in PD patients. Better body composition seems to be associated with physical activity in PD and with physical capacity in CKD patients. Routine clinical management should include a close evaluation of nutritional status and evaluation of physical activity and capacity which can be easily assessed by RAPA and 30"STS tests.

\section{Abbreviations \\ APD: Automated peritoneal dialysis; BIA: Bio-impedance analysis; CAPD: Continuous peritoneal dialysis; CCl: Charlson comorbidity index; CKD: Chronic kidney disease; CNQA: Council of nutrition appetite questionnaire; eGFR: estimated glomerular filtration rate; ESRD: End-stage renal disease; GNRI: Geriatric nutritional risk index; IQR: Median and inter- quartile range (IQR); MIS: Malnutrition-inflammation score; PD: Peritoneal dialysis; RAPA: Rapid assessment of physical activity; SD: Standard deviation; STS: Sit-to-stand}

\section{Acknowledgement}

Authors are gratefully indebted for collaboration to M.ITO.-DP group * Mencherini A, Bruzzichelli G, Marzocchi A (3); Caselli GM, Mecacci A, Bernardi M (2); Michelassi S, Benedetti I, Bonini S (4); Belluardo M, Tozzi A, Papi A (5); Cioni A, Sordini C, Rolle D (6); Carlini A, Lucarotti I, Lucarini R (7); Barattini M, 
Sposini S, Briglia M, Ceccarelli F (8); Del Corso C, Lunardi W, Betti G (9); Catania B, Carlotti E, Buglioni S (10); Egidi MF, Bottai A, Onnis FE (1); Aterini S, Errichiello F, Colzi C (11); Finato V, Bianchi S, Fogli R (12); Cappelletti F, Mechini C, Redi A (13); Santori F, Cassioli F; (14); Giovannetti E, Giannini S, Malacarne N (15).

1. Dipartimento di Medicina Clinica e Sperimentale, Università di Pisa; AOUP.

2. S.C. Nefrologia e Dialisi, Osp. San Giovanni di Dio, USL Centro Toscana,

Firenze.

3. UO Nefrologia e Dialisi, USL Sud-Est Toscana, Arezzo.

4. S.C. Nefrologia e Dialisi, Osp. S.Maria Annunziata, USL Centro Toscana, Firenze.

5. U.O.C. Nefrologia e Dialisi, USL Sud-Est Toscana, Grosseto.

6. U.O. di Nefrologia e Dialisi, Spedali Riuniti, USL Nord-Ovest Toscana,

Livorno.

7 U.O. Nefrologia e Dialisi, Ospedale S. Luca; USL Nord-Ovest Toscana -

Lucca.

8 U.O. Nefrologia ed Emodialisi, USL Nord-Ovest Toscana, Massa/Carrara.

9 U.O. Nefrologia e Dialisi, USL Centro Toscana, Pistoia.

10 U.O.S. Dialisi, USL Nord-Ovest Toscana, Pontedera.

11 U.O. Nefrologia, Osp. S. Stefano, USL Centro Toscana - Prato.

12 U.O.C. Nefrologia e Dialisi, Osp. degli Infermi, USL Centro Toscana - S. Miniato.

13 UOC Nefrologia Dialisi e Trapianto, AOUS; Siena.

14 S.S Dialisi e Nefrologia, Ospedali Riuniti, USL Sud-Est, Valdichiana.

15 U.O.C. Nefrologia e Dialisi USL Nord-Ovest Toscana - Versilia.

\section{Funding}

Research grant from the University of Pisa.

\section{Availability of data and materials}

The datasets used and/or analysed during the current study are available from the corresponding author on reasonable request.

\section{Authors' contributions}

AC, CDA made substantial contributions to conception and design, and drafting the manuscript. VF, CDC, BA, GMC, MFE have been involved in data collection and in drafting and revising the manuscript critically for important intellectual content. All authors read and approved the final manuscript.

\section{Competing interests}

None of the authors have competing interests regarding the manuscript. AC is an editorial board member of BMC Nephrology.

\section{Consent for publication}

Not applicable.

\section{Ethics approval and consent to participate}

The study is in accordance with Helsinki Declaration. The study protocol has been approved by the Local Ethics Committee of Pisa University Hospital. Participants gave their informed consent.

\section{Publisher's Note}

Springer Nature remains neutral with regard to jurisdictional claims in published maps and institutional affiliations.

\section{Author details}

${ }^{1}$ Department of Clinical and Experimental Medicine, University of Pisa, Via Roma 67, 56126 Pisa, Italy. ${ }^{2}$ Nephrology and Dialysis Unit, S. Miniato Hospital, S. Miniato, Italy. ${ }^{3}$ Nephrology and Dialysis Unit, Pistoia Hospital, Pistoia, Italy. ${ }^{4}$ Nephrology and Dialysis Unit, Pontedera Hospital, Pontedera, Italy.

${ }^{5}$ Nephrology and Dialysis Unit, S. Giovanni di Dio Hospital, Florence, Italy.

Received: 11 January 2017 Accepted: 17 May 2017

Published online: 30 May 2017

\section{References}

1. Cupisti A, D'Alessandro C, Fumagalli G, Vigo V, Meola M, Cianchi C, et al. Nutrition and physical activity in CKD patients. Kidney Blood Press Res. 2014; 39:107-13.
2. Clyne $N$, Jogestrand $T$, Lins L, Pehrsson S, Ekelund L. Factors limiting physical working capacity in predialytic uraemic patients. Acta Med Scand. 1987;222:183-90.

3. Heiwe $\mathrm{S}$, Jacobson $\mathrm{SH}$. Exercise training for adults with chronic kidney disease. Cochrane Database Syst Rev. 2011;10:CD003236.

4. O'Hare AM, Tawney K, Bacchetti P, Johansen KL. Decreased survival among sedentary patients undergoing dialysis: results from the dialysis morbidity and mortality study wave 2. Am J Kidney Dis. 2003;41:447-54.

5. Johansen KL, Kaysen GA, Dalrymple LS, Grimes BA, Glidden DV, Anand S, et al. Association of physical activity with survival among ambulatory patients on dialysis: the comprehensive dialysis study. Clin J Am Soc Nephrol. 2013;8:248-53.

6. Matsuzawa R, Matsunaga A, Wang G, Kutsuna T, Ishii A, Abe Y, et al. Habitual physical activity measured by accelerometer and survival in maintenance hemodialysis patients. Clin J Am Soc Nephrol. 2012;7:2010-6.

7. Fouque D, Kalantar-Zadeh K, Kopple J, Cano N, Chauveau P, Cuppari L, et al. A proposed nomenclature and diagnostic criteria for protein-energy wasting in acute and chronic kidney disease. Kidney Int. 2008;73:391-8.

8. Tennankore KK, Bargman JM. Nutrition and the kidney: recommendations for peritoneal dialysis. Adv Chronic Kidney Dis. 2013;20:190-201.

9. Castrale C, Evans D, Verger C, Fabre E, Aguilera D, Ryckelynck JP, et al. Peritoneal dialysis in elderly patients: report from the French peritoneal dialysis registry (RDPLF). Nephrol Dial Transplant. 2010;25:255-62.

10. Topolski TD, LoGerfo J, Patrick DL, Williams B, Walwick J, Patrick MB. The rapid assessment of physical activity (RAPA) among older adults. Prev Chronic Dis. 2006:3:1-8.

11. Macfarlane DJ, Chou KL, Cheng YH, Chi I. Validity and normative data for thirty second chair stand test in elderly community-dwelling Hong Kong Chinese. Am J Hum Biol. 2006;18:418-21.

12. Jones CJ, Rikli RE, Beam WC. A 30-s chair-stand test as a measure of lower body strength in community-residing older adults. Res Q Exerc Sport. 1999:70:113-9.

13. Bazanelli AP, Kamimura MA, Manfredi SR, Draibe SA, Cuppari L. Usefulness of waist circumference as a marker of abdominal adiposity in peritoneal dialysis: a cross-sectional and prospective analysis. Nephrol Dial Transplant. 2012;27:790-5.

14. Fürstenberg A, Davenport A. Assessment of body composition in peritoneal dialysis patients using bioelectrical impedance and dual-energy x-ray absorptiometry. Am J Nephrol. 2011:33:150-6.

15. Saragat B, Buffa R, Mereu E, De Rui M, Coin A, Sergi G, et al. Specific bioelectrical impedance vector reference values for assessing body composition in the Italian elderly. Exp Gerontol. 2014;50:52-6.

16. Afşar B, Sezer S, Ozdemir FN, Celik H, Elsurer R, Haberal M. Malnutritioninflammation score is a useful tool in peritoneal dialysis patients. Perit Dial Int. 2006;26:705-11.

17. He T, An X, Mao HP, Wei X, Chen JH, Guo N, et al. Malnutritioninflammation score predicts long-term mortality in Chinese PD patients. Clin Nephrol. 2013;79:477-83.

18. Wilson MM, Thomas DR, Rubenstein LZ, Chibnall JT, Anderson S, Baxi A, et al. Appetite assessment: simple appetite questionnaire predicts weight loss in community-dwelling adults and nursing home residents. Am J Clin Nutr. 2005; 82:1074-81.

19. Szeto CC, Kwan BC, Chow KM, et al. Geriatric nutritional risk index as a screening tool for malnutrition in patients on chronic peritoneal dialysis. J Ren Nutr. 2010;20:29-37.

20. Kang $\mathrm{SH}, \mathrm{Cho} \mathrm{KH}$, Park JW, et al. Geriatric nutritional risk index as a prognostic factor in peritoneal dialysis patients. Perit Dial Int. 2013;33:405-10.

21. Panichi V, Cupisti A, Rosati A, et al. Geriatric nutritional risk index is a strong predictor of mortality in hemodialysis patients: data from the Riscavid cohort. J Nephrol. 2014;27:193-201.

22. Yamada K, Furuya R, Takita T, Maruyama Y, Yamaguchi Y, Ohkawa S, et al. Simplified nutritional screening tools for patients on maintenance hemodialysis. Am J Clin Nutr. 2008:87:106-13.

23. Cobo G, Gallar P, Gama-Axelsson T, Di Gioia C, Qureshi AR, Camacho R, et al Clinical determinants of reduced physical activity inhemodialysis and peritoneal dialysis patients. J Nephrol. 2015;28:503-10.

24. Cupisti A, Capitanini A, Betti G, D'Alessandro C, Barsotti G. Assessment of habitual physical activity and energy expenditure in dialysis patients and relationships to nutritional parameters. Clin Nephrol. 2011:75:218-25.

25. Mafra D, Deleaval P, Teta D, Cleaud C, Perrot MJ, Rognon S, et al. New measurements of energy expenditure and physical activity in chronic kidney disease. J Ren Nutr. 2009;19:16-19. 
26. Mayer CJ, Steinman L, Williams B, Topolski TD, LoGerfo J. Developing a telephone assessment of physical activity (TAPA) questionnaire for olderadults. Prev Chronic Dis. 2008;5:1-7.

27. Oishi D, Koitabashi K, Hiraki K, Imai N, Sakurada T, Konno Y, et al. Physical activity is associated with serum albumin in peritoneal dialysis patients. Adv Perit Dial. 2012;28:148-52.

28. Mafra D, Deleaval P, Teta D, Cleaud C, Arkouche W, Jolivot A, et al. Influence of inflammation on total energy expenditure in hemodialysis patients. J Ren Nutr. 2011;21:387-93.

29. Anand S, Chertow GM, Johansen KL, Grimes B, Kurella Tamura M, Dalrymple LS, et al. Association of self-reported physical activity with laboratory markers of nutrition and inflammation: the comprehensive dialysis study. J Ren Nutr. 2011;21:429-37.

30. Viana JL, Kosmadakis GC, Watson EL, Bevington A, Feehally J, Bishop NC, et al. Evidence for anti-inflammatory effects of exercise in CKD. J Am Soc Nephrol. 2014;25:2121-30.

31. Lee SJ, Yoo JS. The effects of a physical activity reinforcement program on exercise compliance, depression, and anxiety in continuous ambulatory peritoneal dialysis patients. Taehan Kanho Hakhoe Chi. 2004;34:440-8.

32. Manfredini F, Lamberti N, Malagoni AM, Felisatti M, Zuccalà A, Torino C, et al. The role of deconditioning in the end-stage renal disease myopathy: physical exercise improves altered resting muscle oxygen consumption. Am J Nephrol. 2015;41:329-36.

33. Garibotto G, Sofia A, Saffioti S, Bonanni A, Mannucci I, Parodi EL, et al. Effects of peritoneal dialysis on protein metabolism. Nutr Metab Cardiovasc Dis. 2013;23(Suppl 1):S25-30.

34. Delgado C, Johansen KL. Barriers to exercise participation among dialysis patients. Nephrol Dial Transplant. 2012;27:1152-7.

35. Fiaccadori E, Sabatino A, Schito F, Angella F, Malagoli M, Tucci M, et al. Barriers to physical activity in chronic hemodialysis patients: a single-center pilot study in an Italian dialysis facility. Kidney Blood Press Res. 2014;39:169-75.

36. Padilla J, Krasnoff J, Da Silva M, Hsu CY, Frassetto L, Johansen KL, et al. Physical functioning in patients with chronic kidney disease. J Nephrol. 2008;21:550-9

37. Hellberg $M$, Höglund $P$, Svensson P, Abdulahi H, Clyne N. A decline in measured GFR is associated with a decrease in endurance, strength, balance and fine motor skills. Nephrology (Carlton). 2016. doi:10.1111/nep.12810.

38. Zhou Y, Hellberg M, Svensson P, Höglund P, Clyne N. Sarcopenia and relationships between muscle mass, measured glomerular filtration rate and physical function in patients with chronic kidney disease stages 3-5. Nephrol Dial Transplant. 2017. doi:10.1093/ndt/gfw466.

39. Taskapan H, Baysal O, Karahan D, Durmus B, Altay Z, Ulutas O. Vitamin D and muscle strength, functional ability and balance in peritoneal dialysis patients with vitamin D deficiency. Clin Nephrol. 2011;76:110-6.

\section{Submit your next manuscript to BioMed Central and we will help you at every step:}

- We accept pre-submission inquiries

- Our selector tool helps you to find the most relevant journal

- We provide round the clock customer support

- Convenient online submission

- Thorough peer review

- Inclusion in PubMed and all major indexing services

- Maximum visibility for your research

Submit your manuscript at www.biomedcentral.com/submit
Biomed Central 